\section{PERCEPTION OF PHYSICAL CHILD ABUSE IN A FRENCH EMERGENCY DEPARTMENT IN 2013-2014}

${ }^{1,2}$ Marion Bailhache, ${ }^{2,3}$ Ahmadou Alioum, ${ }^{2,3,4}$ Louis-Rachid Salmi. ${ }^{1} \mathrm{CHU}$ De Bordeaux, Pole De Pediatrie, France; ${ }^{2}$ Université De Bordeaux, ISPED, Centre INSERM U897-EpidemiologieBiostatistique, France; ${ }^{3}$ INSERM, ISPED, Centre INSERM U897-Epidemiologie-Biostatistique, France; ${ }^{4} \mathrm{CHU}$ De Bordeaux, Pole De Sante Publique, Service D'information Medicale, France

10.1136/injuryprev-2016-042156.438

Background The perception of abuse might explain why France has not prohibited all forms of corporal punishment; it has potential important implications on uses of corporal punishment, intention to report abuse cases and acceptability of laws or prevention programs. The aim of our study was to compare perception of physical child abuse between professionals and parents in an emergency department and determine which characteristics are associated with this perception.

Methods A cross-sectional study was conducted from November 2013 to October 2014 in the emergency department of the Bordeaux paediatric university hospital, France. An anonymous selfquestionnaire, including vignettes describing hypothetic situations of potential physical child abuse and items related to socio-demographic and family characteristics, was administered to professionals and parents. Vignettes included varying child's age, child's behaviour, frequency of caregiver's behaviour, hitting with/without an object, and child's target body part. Respondents were asked to rate the acceptability of situations of eight random vignettes on a $100-\mathrm{mm}$ visual analogic scale. Analyses were multivariate mixed Poisson regressions.

Results One thousand and one participants assessed the vignettes. Participants were predominantly female (64\%), married or living with a partner $(87 \%)$, with a median age of 34 years. Professionals significantly assessed vignettes as more acceptable than parents (mean rating multiplied by $2.8 ; p<0.001$ ). Parents who had a child under one-year-old (multiplied by 0.7 ), those who had consulted many times in the past year (multiplied by 0.7 ), and those who had less children, were less tolerant. All vignette characteristics were significantly associated with the acceptability.

Conclusions Such differences indicate the need for additional research to better appreciate consequences and severity of physical violence toward children, and the need to educate parents and professionals.

\section{PERCEPTIONS AND PERSPECTIVES OF CHILD MALTREATMENT IN BANGLADESH: A PILOT STUDY}

Syed Moniruzzaman, Ulla-Britt Eriksson, Staffan Janson. Karlstad University, Sweden

10.1136/injuryprev-2016-042156.439

Background Child maltreatment is a complex issue, and defining the phenomenon is a great challenge. While the definitions used in literature today are mostly intended to operationalize in western societies, are less understood to developing country contexts. This study aims to explore the perceptions of child maltreatment by children, parents, school teachers, owners of workplace and child right professionals in Bangladesh, and to understand psychological, physical and social consequences of maltreatment.

Methods Qualitative semi-structured interviews and key informant interviews were used to collect data materials. The study population was strategically selected from designated areas comprising samples of school going vs non-school going, urban vs rural, low vs high socioeconomic combinations. A total of 51 persons participated in interviews ( 24 children, 16 parents, 6 school teachers, and 5 owners); 1 professional participated in key informant interview. Qualitative content analysis is used to analyse the data.

Results A strong cultural difference in child abuse was indicated in child perception. Children were abused repeatedly in various forms, with abuse in childhood shifted from home to workplace when becoming adolescent. It seems as not firstly being physical punished, but instead; they were being used/exploited with no or very little salary, late payments and/or threatened not to be paid, notice to quit the job, deduction of salary, and accusations for being lazy, broken things/glasses, etc. without reason. Poverty and strict disciplinary actions taken by caregivers found to be associated with school dropout.

Conclusions This study accomplishes two goals: it highlights the cultural context in defining the child maltreatment in a developing country's perspective. More importantly, the study addresses an area that has formerly been ignored and less understood in countries such as Bangladesh, and brings the issue in a public health perspective.

\section{DIVERSITY, MIGRATION AND CHILD PROTECTION}

${ }^{1}$ Julie Taylor, ${ }^{2}$ Fungisai Puleng Ottemöller, ${ }^{2}$ Ragnhild Hollekim, ${ }^{3}$ Kay Tisdall. ${ }^{1}$ University of Birmingham, UK; ${ }^{2}$ University of Bergen, Norway; ${ }^{3}$ University of Edinburgh, UK

\subsection{6/injuryprev-2016-042156.440}

Background Child maltreatment is a major global public health and safety issue, with short and long term adverse consequences for individuals, communities and society generally. Children and families affected by migration are more vulnerable to maltreatment due to numerous reasons including reduced resources, increased psychosocial pressures, trauma, displacement and bereavement. Policymakers and practitioners sometimes struggle to find a balance between respect for diverse cultural customs and keeping a child safe. Numerous child homicides occur across the world where cultural sensitivity and fear of repercussion meant that early warnings of maltreatment were missed and opportunities to prevent child maltreatment or deaths were lost. At the same time, blanket policies addressing issues particularly pertinent to some migrant children, for example radicalization, female genital cutting, may provoke further distancing between some ethnic groups and services that might address children's safety needs.

Methods An integrative review of child maltreatment reports was undertaken from selected available serious case reviews, child death reports and child protection databases. Major literature on diversity, migration and child protection was examined for critical comment and best practice examples. Relevant policy documents were also scrutinised. Five diverse exemplar case studies were interrogated in depth to consider the linkages between diversity, migration and child protection. Inductive thematic analysis organised emergent themes within a human factors and safety framework.

Results Extant literature is myriad, multidisciplinary and diverse. There is a paucity of empirical research addressing the linkages between migration, diversity and child protection. Whilst there is a difference between the needs of refugee and asylum-seeking children and young people and those of settled first or second generations, there are more commonalities than might be thought. Thematic overviews of significant cases illuminate tensions in responding adequately to issues of child maltreatment where cultural difference prevents helpful dialogue in enhancing child safety. 